\title{
Carcinoid heart disease: correlation of echocardiographic and histopathological findings
}

\author{
Lachlan Fraser Miles, ${ }^{1}$ Trishe Leong, ${ }^{2}$ Peter McCall, ${ }^{1}$ Laurence Weinberg ${ }^{1,3}$
}

'Department of Anaesthesia, Austin Health, Melbourne, Victoria, Australia

${ }^{2}$ Department of Anatomical Pathology, Austin Health, Melbourne, Victoria, Australia ${ }^{3}$ Department of Surgery, University of Melbourne, Melbourne, Victoria, Australia

\section{Correspondence to}

A/Prof Laurence Weinberg, laurence.weinberg@austin. org.au

Accepted 6 November 2014
CrossMark

\footnotetext{
To cite: Miles $L F$, Leong $T$, McCall $\mathrm{P}$, et al. BMJ Case Rep Published online: [please include Day Month Year] doi:10.1136/bcr-2014207732
}

\section{DESCRIPTION}

A 41-year-old man presented to an anaesthetic preassessment clinic with a metastatic neuroendocrine tumour and clinical features of carcinoid syndrome for consideration of hepatic resection. He gave a history of worsening exertional dyspnoea and peripheral oedema. A loud systolic murmur was audible over the right sternal edge. Transthoracic echocardiography revealed severe tricuspid and pulmonic regurgitation and right ventricular volume overload consistent with carcinoid heart disease, necessitating double valve replacement.

Intraoperative transoesophageal echocardiography (figure 1A) demonstrated thickening and retraction of the tricuspid valve leaflets. Colour flow Doppler (figure 1B) revealed torrential tricuspid regurgitation. Three-dimensional imaging in systole (figure 1C) and diastole (figure 1D) shows minimal motion of the tricuspid valve over the cardiac cycle, and a large regurgitant orifice area.
Histopathological analysis of the excised cardiac valves demonstrated thickening of valve leaflets due to carcinoid plaques, composed of a proliferation of myofibroblasts and the deposition of a myxoid extracellular matrix (figure 2A, B).

Valvular dysfunction in carcinoid heart disease is caused by proliferation of endocardial fibroblasts in response to chronic inflammation, or induced by circulating vasoactive mediators. ${ }^{1}$ Deposition of plaques on the valve leaflets and subvalvular apparatus results in thickening, retraction, impaired leaflet motion and greatly enhanced echogenicity. ${ }^{2}$

Carcinoid heart disease is a challenge for anaesthetists, because of right ventricular failure and the risk of intraoperative carcinoid crisis. This manifests as severe bronchospasm, hypertension or hypotension, and is associated with mortality of up to $18 \% .^{3}$ With appropriate preventative measures, our patient encountered no serious intraoperative issues, was discharged from intensive care unit $24 \mathrm{~h}$
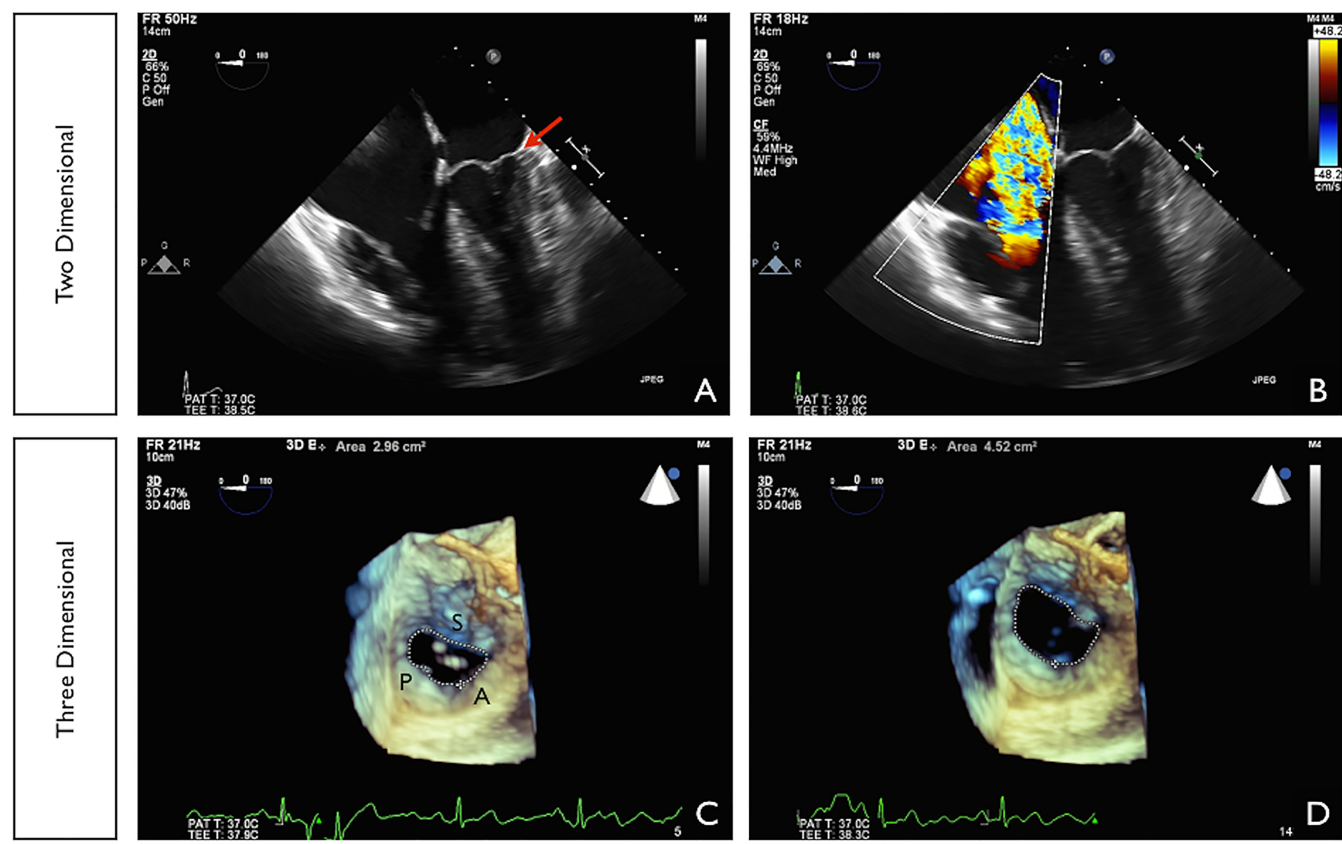

Figure 1 Two-dimensional imaging demonstrates a tricuspid valve fixed open in systole (A). The red arrow points to the normal mitral valve. Colour flow Doppler, again during systole showing severe tricuspid regurgitation (B). Three-dimensional imaging in systole (C) and diastole (D) showing relatively little change in the orifice area during the cardiac cycle. The approximate positions of the septal $(S)$, posterior $(P)$ and anterior $(A)$ tricuspid valve leaflets are shown. 

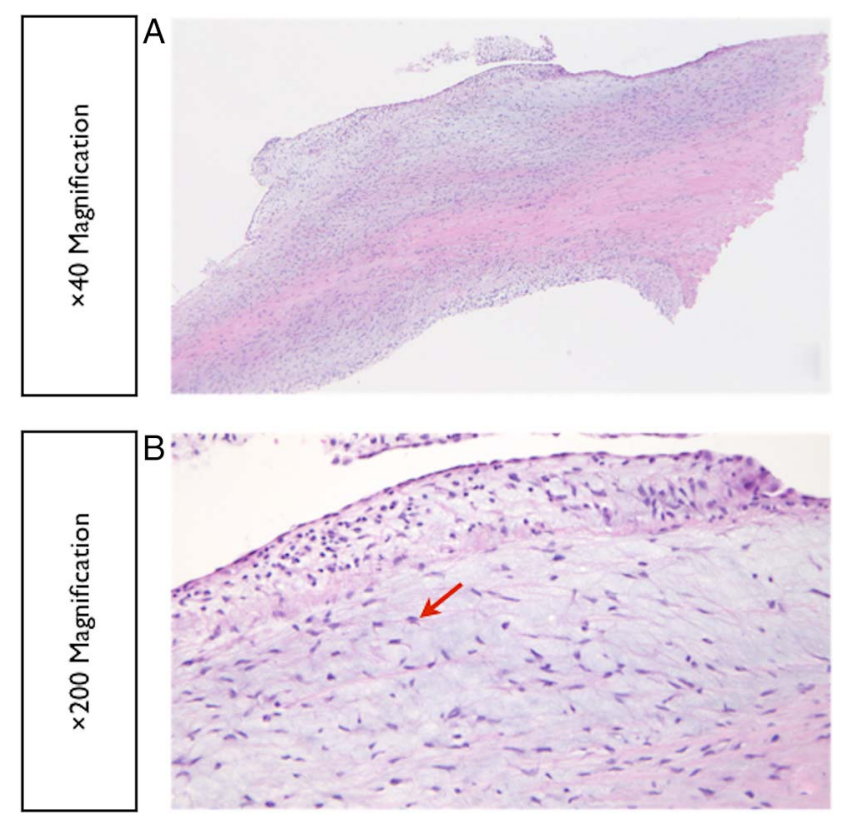

Figure 2 The pulmonic valve (stained with $\mathrm{H} \& \mathrm{E}$ ) is shown at $\times 40(\mathrm{~A})$ and $\times 200$ (B) magnification. The leaflet is grossly thickened by carcinoid plaque, composed of myofibroblasts (red arrow) surrounded by a myxoid matrix.

after his procedure, and eventually to home on postoperative day 5 . Now 4 months postprocedure, he is asymptomatic, and has returned to work. Clinicians managing patients with carcinoid syndrome should be aware of the high incidence of carcinoid heart disease and the implications for anaesthesia and surgery.

\section{Learning points}

- Echocardiography imaging in carcinoid heart disease demonstrates the classical findings of thickening and retraction of the valve leaflets with coaptation failure due to plaque deposition.

- The right-sided valves are usually affected in isolation as the pulmonary circulation filters out vasoactive mediators released by the tumour.

- About $50 \%$ of patients with carcinoid syndrome will develop carcinoid heart disease. Clinicians involved in the management of patients with carcinoid syndrome must be aware of this high incidence and investigate appropriately.

Acknowledgements The authors would like to thank Associate Professor George Matalanis, Director of Cardiac Surgery at our institution, for his most helpful insights regarding the manuscript.

Contributors LFM wrote the manuscript and was involved in patient care. TL interpreted the histopathology and provided the associated description. PM and LW were involved in patient care and assisted in revision of the manuscript.

Competing interests None.

Patient consent Obtained.

Provenance and peer review Not commissioned; externally peer reviewed.

\section{REFERENCES}

1 Simula DV, Edwards WD, Tazelaar HD, et al. Surgical pathology of carcinoid heart disease: a study of 139 valves from 75 patients spanning 20 years. Mayo Clin Proc 2002;77:139-47.

2 Abi-Saleh B, Schoondyke JW, Abboud L, et al. Tricuspid valve involvement in carcinoid heart disease. Echocardiography 2007;4:439-42.

3 Castillo JG, Filsoufi F, Adam DH, et al. Management of patients undergoing multivalvular surgery for carcinoid heart disease: the role of the anaesthesist. Br J Anaesth 2008;101:618-26.

Copyright 2014 BMJ Publishing Group. All rights reserved. For permission to reuse any of this content visit

http://group.bmj.com/group/rights-licensing/permissions.

BMJ Case Report Fellows may re-use this article for personal use and teaching without any further permission.

Become a Fellow of BMJ Case Reports today and you can:

- Submit as many cases as you like

- Enjoy fast sympathetic peer review and rapid publication of accepted articles

- Access all the published articles

- Re-use any of the published material for personal use and teaching without further permission

For information on Institutional Fellowships contact consortiasales@bmjgroup.com

Visit casereports.bmj.com for more articles like this and to become a Fellow 